\title{
COVID-19 INFECTION IN A PATIENT WITH LUPUS PROGRESSING TO VERTEBRAL ARTERY DISSECTION AND ISCHEMIC STROKE
}

\author{
Raiza Cansian Tuão1,*, Paula dos Santos Athayde ${ }^{1}$, Ketty Lysie Libardi Lira Machado ${ }^{1}$, Bárbara Ferraço Dalmaso1, Gustavo Pinto \\ de Oliveira Gomes ${ }^{1}$, Débora Marques Veghini ${ }^{1}$, Estephania Pignaton Naseri ${ }^{1}$, Ruben Horst Duque ${ }^{1}$, Lídia Balarini da Silva ${ }^{1}$, Ana \\ Paula Espíndula Gianordoli ${ }^{1}$, Luiza Correa Rodrigues Dalpiero ${ }^{1}$, Érica Vieira Serrano ${ }^{1}$, Weider Andrade Tomé1, Luiza Vallory

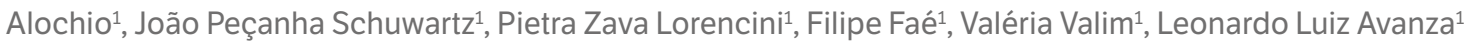

1.Hospital Universitário Cassiano Antonio Moraes, Vitória (ES), Brazil.

*Corresponding author: raizatuao@hotmail.com

\section{BACKGROUND}

Arterial dissection is a rare manifestation of COVID-19 infection, caused by coagulopathy and endothelial dysfunction secondary to exaggerated systemic inflammation. In patients with systemic lupus erythematosus (SLE), the presence of lupus anticoagulant (LAC) can cause endothelial dysfunction through the interaction of antiphospholipid antibodies and endothelial cells, which can lead to arterial dissection, especially in the coexistence of vasculitis. We report a case of a lupus patient with positive LAC who developed spontaneous dissection of the right vertebral artery after COVID-19 infection.

\section{CASE REPORT}

This case concerns a 33-year-old female patient diagnosed with SLE in 2018, presenting with antinuclear antibody (ANA) >1:640, homogeneous nuclear pattern, anti-DNA 1:80, positive lupus anticoagulant, complement consumption, alopecia, oral ulcers, serositis with pericardial and pleural effusion, polyarthritis and lupus nephritis. She was on daily use of hydroxychloroquine $400 \mathrm{mg}$, azathioprine $100 \mathrm{mg}$ and prednisone $5 \mathrm{mg}$, with good control of symptoms, but abandoned treatment in September 2020. She was admitted in April 2021, with altered renal function, anasarca, proteinuria of $5.4 \mathrm{~g}$ in $24 \mathrm{~h}$, and presence of hematic and granular casts in the urine. The patient was given pulse therapy with methylprednisolone and cyclophosphamide, and after 11 days developed headache, dry cough and fever. She was diagnosed with COVID-19 based on symptoms and positive rapid antigen test. Presented mild pneumopathy compromising $25 \%$ both lungs under prednisone $1 \mathrm{mg} / \mathrm{kg} / \mathrm{day}$, and showed good evolution for COVID-19 without any oxygen supplementation. Ten days after, she progressed with nausea, vomiting, dizziness, ataxia in right half of the body, and bilateral horizontal nystagmus. Magnetic resonance imaging (MRI) of the skull showed ischemia of lateral bulb and right cerebellum (Figure 1) and magnetic resonance angiography (MRA) showed dissection of the right vertebral artery. During hospitalization, the patient had an improvement of symptoms, and was discharged for outpatient follow-up and maintenance of pulse therapy with cyclophosphamide.

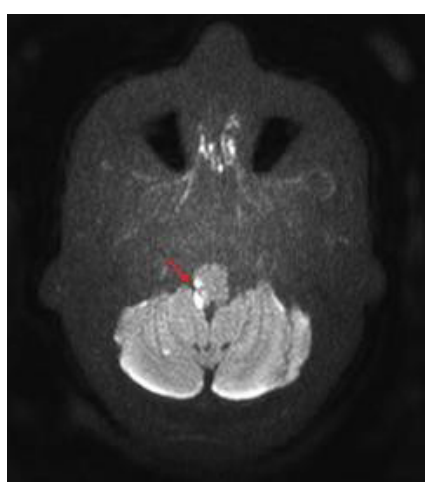

Figure 1. Magnetic resonance imaging of the skull showed acute ischemic lesions compromising the right dorsolateral surface of the medullary bulb (red arrow).

\section{CONCLUSION}

We present the case of a patient with SLE, who, after infection with COVID-19, developed right vertebral artery dissection and consequent ischemic stroke. It is possible that antiphospholipid antibodies may have induced or aggravated an arteriopathy underlying the COVID-19 infection. Therefore, it is important to value neurological symptoms and investigate them appropriately in patients with lupus and positive LAC, especially in the face of the new coronavirus pandemic.

\section{KEYWORDS}

Ischemic stroke, Vertebral artery dissection, Infections, Skull. 